\title{
A Family with Complete Deficiency of Plasma Cholesteryl Ester Transfer Protein Activities
}

\author{
Hironi Makita, Masahiro TsujI, Yukiko Furuya, Keiko TsuchiHashi*, \\ Harukuni AKITA** and Hitoshi CHIBA**
}

\begin{abstract}
A 43-year-old male with a high value of high density lipoprotein cholesterol ( $151 \mathrm{mg} / \mathrm{dl}) \mathrm{was}$ found among subjects receiving annual health checks. We investigated the cholesteryl ester transfer protein (CETP) activity and conducted a family study. There was complete deficiency of CETP activities in the proband and l:is sister, and partial deficiency of CETP activities in his mother and daughter. Genetic analysis revealed a splicing defect ( $G$ to $A$ point mutation) in intron 14 of the CETP gene.
\end{abstract}

(Internal Medicine 33: 432-436, 1994)

Key words: HDL cholesterol, atherosclerosis, HDL triglyceride

\section{Introduction}

Epidemiologic studies have shown an inverse correlation between plasma HDL cholesterol levels and atherosclerotic disease (1-3). Several factors, lipoprotein lipase, hepatic triglyceride lipase and cholesteryl ester transfer protein (CETP), have been shown to regulate HDL cholesterol levels (4). CETP deficiency has been shown to be a longevity syndrome $(1,5,6)$. Plasma CETP deficiencies have been found only in Japanese and Koreans (7). The common cause of CETP deficiency among Japanese is a $\mathrm{G}$ to A point mutation of a splicing donor site of intron 14 of the CETP gene (1). This point mutation has been found in the Kanazawa, Iwate, Tokyo, and Osaka areas, but there have been no reports of cases with this mutation from Hokkaido.

The present report is of a family in Hokkaido with complete CETP activity deficiency.

\section{Case Report}

A 43-year-old male with excess high density lipoprotein (HDL) cholesterol $(151 \mathrm{mg} / \mathrm{dl})$ was found among subjects receiving regular annual health checks at the Hokkaido Central Hospital for Social Health Insurance in 1992. He had no history of illness and was not on medication. The physical examination showed him to be normal and the results of laboratory tests were within the normal range, except for hyperlipidemia. There was no family history of metabolic diseases or illnesses. He was
$169.3 \mathrm{~cm}$ high, and weighed $70.2 \mathrm{~kg}$, and did not use alcohol or tobacco, blood pressure was $110 / 70 \mathrm{mmHg}$ and pulse $68 /$ min, both regular. The hematologic values and blood chemical values during the health check are listed in Table 1. The electrocardiogram showed normal rhythm at $60 / \mathrm{min}$, with nonspecific ST-segment and T-wave abnormalities. Radiography of the chest, and ultrasonography of the abdomen yielded normal findings.

\section{Materials and Methods}

Measurement of serum lipoprotein

Blood samples were obtained after an overnight fast. Total

Table 1. Laboratory Findings

\begin{tabular}{lrlr}
\hline RBC & $557 \times 10^{4} / \mathrm{ml}$ & Total cholesterol & $251 \mathrm{mg} / \mathrm{dl}$ \\
$\mathrm{Hb}$ & $16.2 \mathrm{~g} / \mathrm{dl}$ & Triglyceride & $232 \mathrm{mg} / \mathrm{dl}$ \\
$\mathrm{Hct}$ & $48.6 \%$ & HDL cholesterol & $151 \mathrm{mg} / \mathrm{dl}$ \\
$\mathrm{GOT}$ & $15 \mathrm{U} / 1$ & HDL2 cholesterol & $113.2 \mathrm{mg} / \mathrm{dl}$ \\
$\mathrm{GPT}$ & $15 \mathrm{U} / \mathrm{l}$ & HDL3 cholesterol & $15.8 \mathrm{mg} / \mathrm{dl}$ \\
$\gamma \mathrm{GTP}$ & $16 \mathrm{U} / 1$ & HDL2/HDL3 ratio & 7.16 \\
$\mathrm{ALP}$ & $196 \mathrm{U} / 1$ & HDL triglyceride & $3 \mathrm{mg} / \mathrm{dl}$ \\
ZTT & $13.2 \mathrm{KU}$ & CETP activity & $0 \%$ \\
$\mathrm{Cr}$ & $0.9 \mathrm{mg} / \mathrm{dl}$ & PHLA & $0.365 \mathrm{ffa} / \mathrm{ml} / \mathrm{min}$. \\
FPG & $91 \mathrm{mg} / \mathrm{dl}$ & & \\
UA & $6.5 \mathrm{mg} / \mathrm{dl}$ & & \\
\hline
\end{tabular}

PHLA: post heparin lipolytic activity.

From the Department of Internal Medicine, Hokkaido Central Hospital for Social Health Insurance, Sapporo, *the Department of Chemistry, Sapporo Medical College, Sapporo and **the Department of Laboratory Medicine, Hokkaido University School of Medicine, Sapporo 


\section{A Family with Complete CETP Deficiency}

cholesterol levels and triglyceride levels were measured enzymatically using commercial kits. The HDL was separated from apo B-containing lipoproteins by using the phosphotungstic acid magnesium precipitation method, as described elsewhere (8). The HDL subfractions were separated by ultra centrifugation.

\section{Measurement of serum CETP activity}

The CETP activity was measured according to the method of Albers et al (9). The $\mathrm{HDL}_{3}$ with ${ }^{14} \mathrm{C}$-labeled cholesteryl esters were used as the donor, and LDL as the acceptor. Ten milliliters of serum was added to the solution containing donor and acceptor as a source of lipid transfer protein. After incubation at $37^{\circ} \mathrm{C}$ for 12 hours, washed plasma $(400 \mathrm{ml})$ was added. The donor $\left(\mathrm{HDL}_{3}\right)$ and acceptor $(\mathrm{LDL})$ were separated by the precipitation method using dextran-magnesium, we measured the radioactivity in the supernatant. Serum CETP activity was determined as the ratio of the blank control.

\section{Analysis of CETP gene of the proband}

Genomic DNA was purified from peripheral white blood cells. The DNA fragment encompassing exon 14 of the CETP gene was amplified with a polymerase chain reaction (PCR) using 84 and 43 base pair (bp) primers. The former was located at the 5 ' end of intron 13, and the latter at the 3 ' end of intron 14. Analysis of restriction fragment length polymorphisms
(RFLPs) was with enzyme Nde I, and polyacrylamide gel electrophoresis using an $8 \%$ polyacrylamide gel.

\section{Results}

Serum lipid, lipoprotein cholesterol, and apolipoprotein levels of the proband

Laboratory findings are shown in Table 1. The serum total cholesterol level was $251 \mathrm{mg} / \mathrm{dl}$, and the HDL cholesterol level was $151 \mathrm{mg} / \mathrm{dl}$. There was no serum CETP activity. The HDL cholesterol was very high $(151 \mathrm{mg} / \mathrm{dl})$, but HDL tryglyceride was lower $(3 \mathrm{mg} / \mathrm{dl})$ than controls $(10.6 \pm 3.2 \mathrm{mg} / \mathrm{dl}$, mean $\pm \mathrm{SD}$, $\mathrm{n}=48)$. The $\mathrm{HDL}_{2}$-cholesterol level was higher $(113.2 \mathrm{mg} / \mathrm{dl})$ than the controls $(17.7 \pm 74.0 \mathrm{mg} / \mathrm{dl}$, mean $\pm \mathrm{SD})$. The $\mathrm{HDL}_{3^{-}}$ cholesterol level was within the normal range $(15.8 \mathrm{mg} / \mathrm{dl})$ of the controls $(10.8 \pm 22.4 \mathrm{mg} / \mathrm{dl}$, mean $\pm \mathrm{SD})$. The $\mathrm{HDL}_{2} / \mathrm{HDL}_{3}$ ratio was elevated (7.16). Serum levels of apolipoproteins A-I, A-II, C-II, and E were elevated. Post heparin lipolytic activity (PHLA) was within the normal range. Thus, the proband was assumed to be a genetic complete CETP deficient type.

\section{Family study}

A family study was carried out (Fig. 1). Serum lipids, CETP activity, and apolipoprotein concentrations of the proband and his family are shown in Table 2 . There was no CETP activity of the proband and his sister. The CETP activity of his mother and

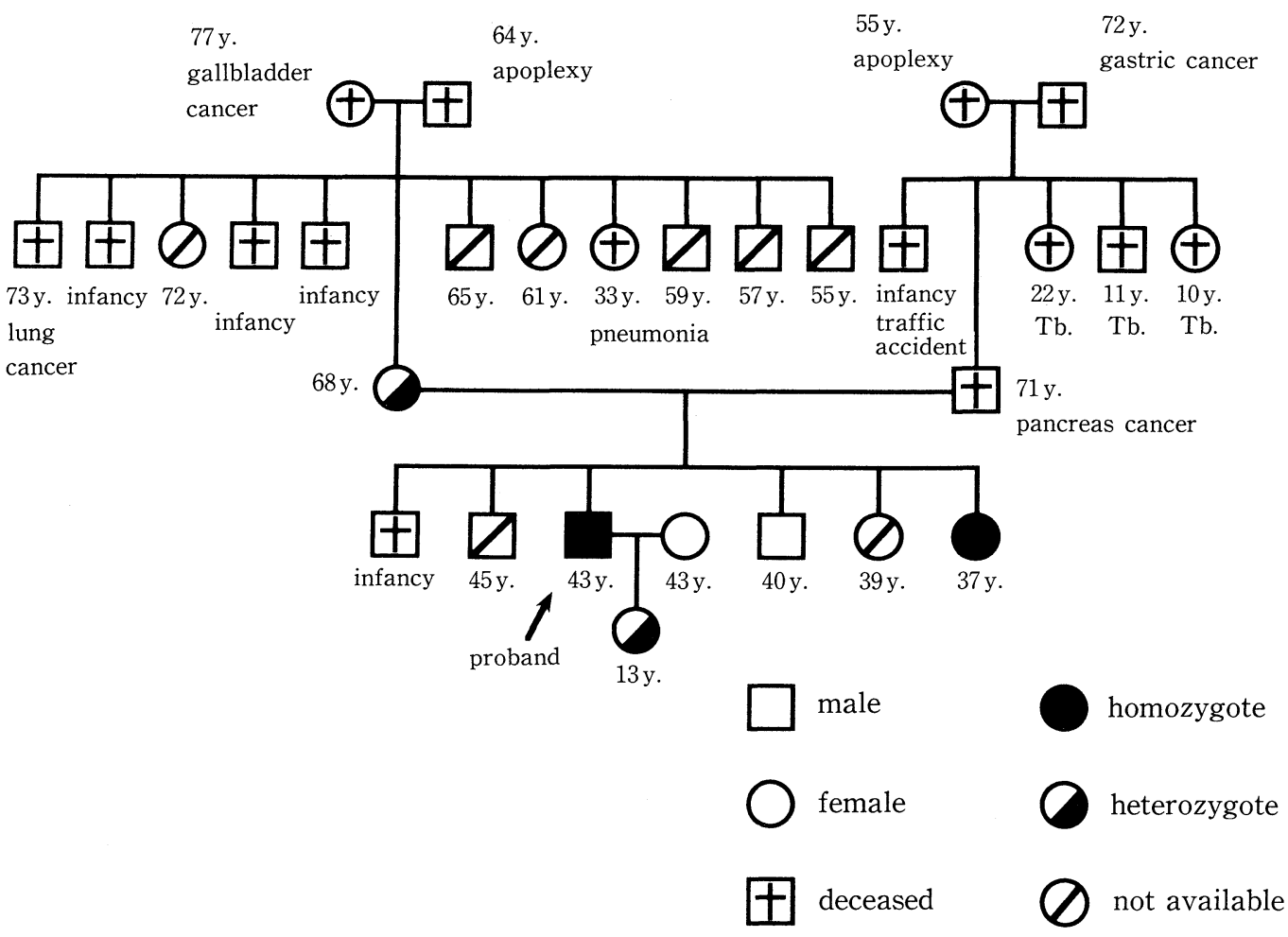

Fig. 1. Family tree. y: years old, Tb: tuberculosis. The proband is indicated by an arrow. The HDL cholesterol of the proband and his sister, both with homozygous CETP deficiency, were $151 \mathrm{mg} / \mathrm{dl}$ and $130 \mathrm{mg} / \mathrm{dl}$, respectively. The CETP activities were null. The HDL cholesterol of his mother and daughter, both with heterozygous CETP deficiency, were $88 \mathrm{mg} /$ $\mathrm{dl}$ and $112 \mathrm{mg} / \mathrm{dl}$, respectively. The CETP activities of his mother and daughter were low. 
Makita et al

Table 2. Serum Lipids, Lipoprotein Cholesterol and Apolipoprotein Levels* of This Family

\begin{tabular}{lccccc}
\hline & Proband & Sister & Mother & Daughter & Wife \\
\hline Age & 43 & 38 & 69 & 15 & 43 \\
Total cholesterol & 251 & 204 & 180 & 221 & 235 \\
HDL-cholesterol & 151 & 130 & 88 & 112 & 67 \\
HDL-triglyceride & 3 & 2 & 8 & 8 & 16 \\
LDL-cholesterol & 53.6 & 53.2 & 79.6 & 94.8 & 139 \\
CETP-activity (\%) & 0 & 0 & 13.4 & 15.5 & 25.4 \\
& & & & & \\
Apolipoprotein A-I & 234 & 204 & 160 & 154 & 135 \\
Apolipoprotein A-II & 44.1 & 40.4 & 37.2 & 32.9 & 36 \\
Apolipoprotein B & 95 & 57 & 66 & 67 & 107 \\
Apolipoprotein C-II & 12.5 & 5.1 & 4.2 & 3.3 & 3.5 \\
Apolipoprotein C-III & 26.7 & 11.7 & 9.1 & 16.4 & 13.1 \\
Apolipoprotein E & 13.9 & 5.3 & 4.5 & 5.5 & 4.2 \\
\hline
\end{tabular}

*Values are in mg/dl. HDL: high density lipoprotein, LDL: low density lipoprotein, CETP: cholesteryl ester transfer protein.

Proband

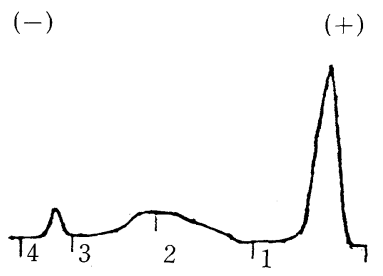

Sister

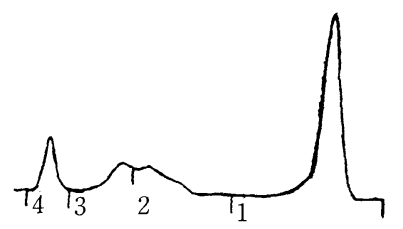

Mother

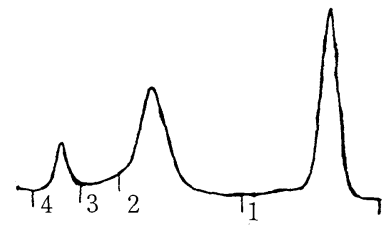

Daughter

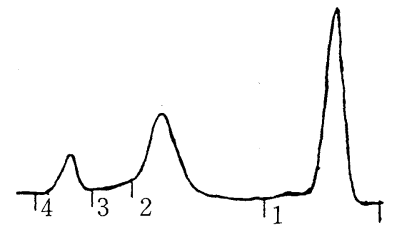

Wife

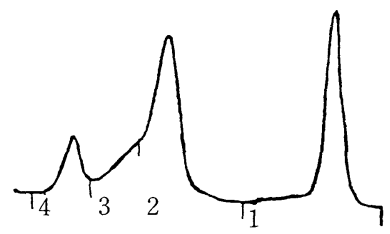

Fig. 2. Lipoprotein fraction patterns of this family showed polydispersity in the proband and his sister. In his mother and his daughter, the peak corresponding to LDL was smaller than that of normal controls. The fraction pattern of his wife was normal. daughter was lower (13.4\% and $15.5 \%$, respectively) than normolipidemic controls $(25.8 \pm 6.02 \%$, mean $\pm \mathrm{SD}, \mathrm{n}=30)$. The serum CETP activity of his wife was within the normal range (25.4\%). The HDL cholesterol of his sister was higher $(130 \mathrm{mg} /$ $\mathrm{dl})$, and her HDL tryglyceride was lower $(2 \mathrm{mg} / \mathrm{dl})$ than the control. Serum apolipoprotein A-I, A-II, C-II, and E were elevated in both proband and sister. Serum apolipoprotein A-I, and $\mathrm{E}$ were elevated in his mother and daughter.

Polyacrylamide gel electrophoresis (PAGE)

The lipoprotein fractions by PAGE showed polydispersity in the proband and his sister (Fig. 2).
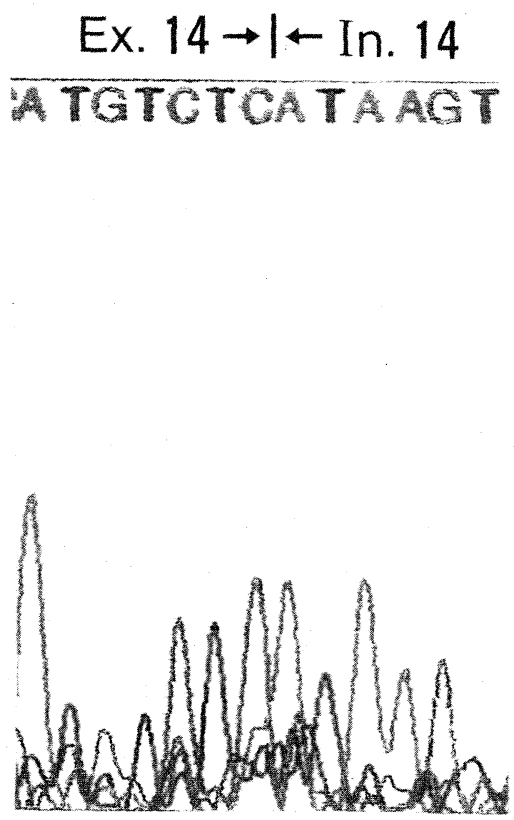

Fig. 3. A splicing defect $(\mathrm{G} \rightarrow \mathrm{A}$ mutation) in intron 14 of the CETP gene was determined. DNA sequences of the exon 14/intron 14 boundary. 


\section{A Family with Complete CETP Deficiency}

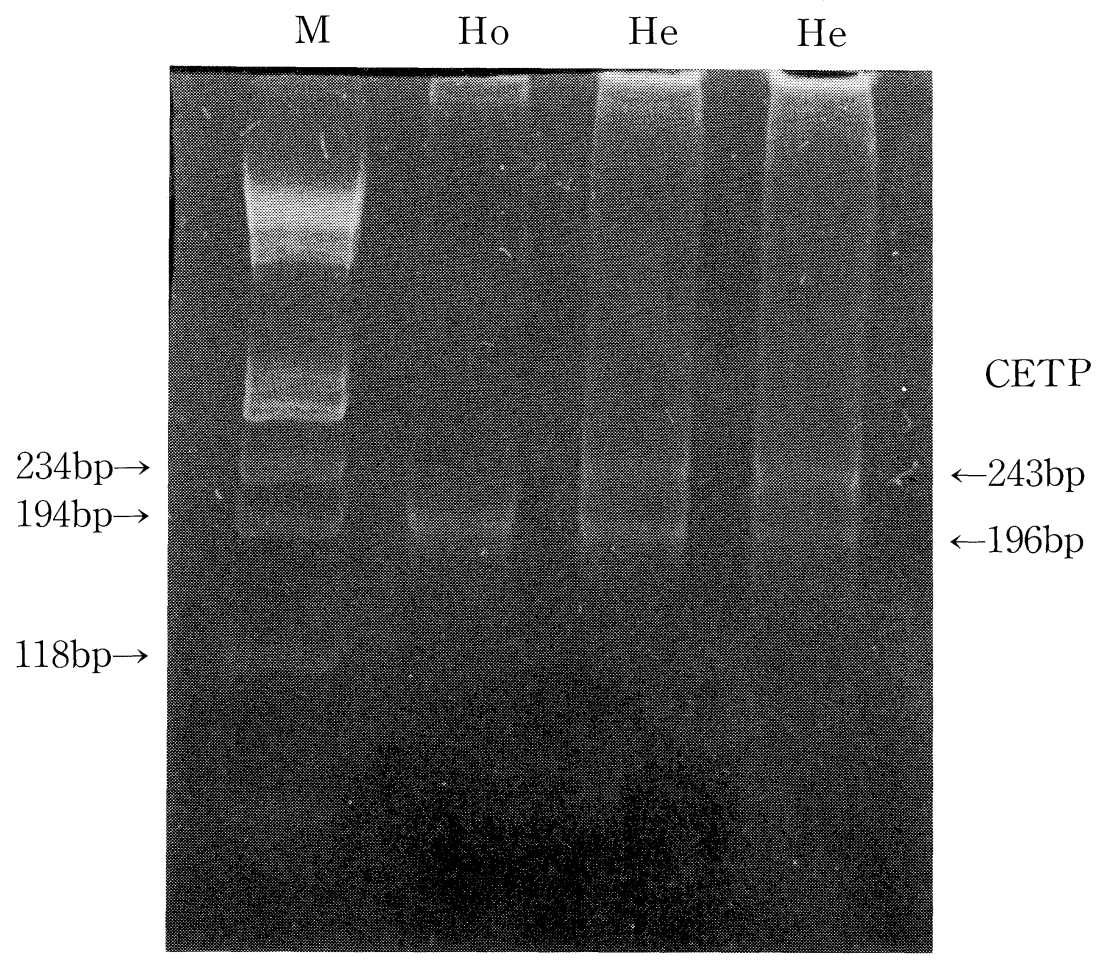

8\% Polyacrylamidegel

Fig. 4. The pattern of PAGE of the CETP locus. The proband showed a $194 \mathrm{bp}$ single band denoted as Ho. His mother and daughter showed double bands of $243 \mathrm{bp}$ and $196 \mathrm{bp}$ denoted as He. The proband was designated a homozygote and his mother and daughter were identified as heterozygotes of this mutation.

\section{Analysis of the CETP gene of the proband}

The proband was found to have a $G$ to A point mutation in intron 14 splicing donor site of the CETP locus (Fig. 3). Genotypes at the CETP locus were determined using RFLPs detected with the enzyme Nde I. The pattern of the PAGE of CETP locus is shown in Fig. 4. The CETP locus with this mutation has been digested into two fragments, $196 \mathrm{bp}$ and 47 bp, by Nde I. The short fragment, $47 \mathrm{bp}$, did not appear with $8 \%$ polyacrylamide gel; the proband showed a $194 \mathrm{bp}$ single band and his mother and daughter double bands of $243 \mathrm{bp}$ and $196 \mathrm{bp}$. Normal subjects with the complete CETP locus would show a single band of $243 \mathrm{bp}$. The proband was designated a homozygote and his mother and daughter were identified as heterozygotes of this mutation.

\section{Discussion}

Familial CETP deficiency is an abnormality of the reverse cholesterol transport systems but it is usually associated with resistance to atherosclerosis $(5,10)$. Extremely high levels of $\mathrm{HDL}$ cholesterol and $\mathrm{HDL}_{2}$ cholesterol are only the sign of this condition. CETP has been shown to transfer cholesterol ester and triglyceride between HDL and VLDL, IDL, and LDL. Despite high levels of HDL cholesterol in CETP deficient patients, HDL triglyceride remains low. The proband and his sister whose CETP activities were completely absent showed extremely high levels of HDL cholesterol and low levels of $\mathrm{HDL}$ triglyceride. The $\mathrm{HDL}_{2} / \mathrm{HDL}_{3}$ cholesterol ratio of the proband was more than 2 times the normal. The HDL cholesterol and HDL triglyceride of his mother and daughter, whose activities of CETP were lower than normal, were between the level of the proband and normal controls. The lipoprotein fraction pattern of PAGE revealed LDL polydispersity only in patients with complete CETP activity deficiency. This shows that only a low activity of CETP can form LDL particles at unidensity size. Analysis of the proband CETP gene showed the G to A point mutation at the splicing donor site of intron 14 , and appeared to be homozygous for the identical haplotype. This point mutation is common in Japanese with CETP deficiency (11-13). Plasma CETP deficiency has been found so far in several subjects in Hokkaido (14), but this case was the first case where the $\mathrm{G}$ to A mutation at the splicing donor site of intron 14 has been shown. The origin of the population of Hokkaido is heterogeneous. The origin of the proband on the mother's side was Aomori prefecture and that on the father's side was Shikoku. This point mutation is thought to be common among Japanese. The CETP deficiency has been thought to be a longevity syndrome $(1,5,6)$. There were no clinical manifes- 


\section{MAKitA et al}

tations of atherosclerosis in the proband and the family members displaying CETP deficiency. The mechanism of CETP deficiency should be further studied and the clinical course of this case will be followed.

\section{References}

1) Inazu A, Brown ML, Hesler CB, et al. Increased high-density lipoprotein levels caused by a common cholesteryl-ester transfer protein gene mutation. N Engl J Med 323: 1234, 1990.

2) Gordon DJ, Rifkind BM. High density lipoprotein - the clinical implications of recent studies. N Engl J Med 321: 1311, 1989.

3) Castelli WP. Epidemiology of coronary heart disease: the Framingham study. Am J Med 76: 4, 1984.

4) Franceschini G, Maderna P, Sirtori CR. Reverse cholesterol transport: physiology and pharmacology. Atherosclerosis 88: 99, 1991.

5) Tall AR. Plasma cholesterol ester transfer protein. J Lipid Res 34: 1255, 1993.

6) Saito F. A pedigree of homozygous familial hyperalphalipoproteinemia. Metabolism 33: 629, 1984.

7) Yamashita S, Matsuzawa Y. Hyper-HDL-cholesterolemia and CETP. Saishinigaku 47: 979, 1992 (in Japanese).
8) Burstein M, Scholnick HF, Morfin R, et al. Rapid method for the isolation of lipoproteins from human serum by precipitation with polyanions. $\mathrm{J}$ Lipid Res 11: 583, 1970.

9) Albers JJ, Tollefson JH, Chen C, et al. Isolation and characterization of human plasma lipid transfer proteins. Arteriosclerosis 4: 49, 1984.

10) Koizumi J, Inazu A, Yagi K, et al. Serum lipoprotein lipid concentration and composition in homozygous and heterozygous patients with cholesteryl ester transfer protein deficiency. Atherosclerosis 90: 189, 1991.

11) Yamashita S, Hui DY, Wetterau JR, et al. Characterization of plasma lipoprotein in patients heterozygous for human plasma cholesteryl ester transfer protein (CETP) deficiency: Plasma CETP regulates high-density lipoprotein concentration and composition. Metabolism 40: 756, 1991.

12) Inazu A, Koizumi J, Haraki T, et al. Rapid detection and prevalence of cholesteryl ester transfer protein deficiency caused by an intron 14 splicing defect in hyperalphalipoproteinemia. Hum Gen 91: 13, 1993.

13) Takegoshi T,Haba T, Kitoh C, etal. Compound heterozygote of cholesterylester transfer protein deficiency in a patient with hyperalphalipoproteinemia. Atherosclerosis 96: 83, 1992.

14) Eto M, Miyata O, Noda K, et al. A case of homozygous familial hyperalphalipoproteinemia with complete deficiency of cholesteryl ester transfer protein activity. J Jpn Atherosclerosis Society 18: 1127, 1990 (in Japanese). 